\title{
Presence of a chorionic gonadotrophin-like factor in mouse placental cultures during the second half of gestation
}

\author{
B. Rao, G. Pointis and L. Cedard \\ U. 166 INSERM, Laboratoire de Chimie Hormonale, Maternité de Port-Royal, \\ 123 Bld de Port-Royal, 75014 Paris, France
}

\begin{abstract}
Summary. Gonadotrophin-like activity in the cultures of mouse placentae, from Days 10 to 18 of gestation, was determined by using a sensitive mouse Leydig cell testosterone bioassay. The limit of detection of the bioassay was 0.05 mi.u. for the 2nd International Standard of hCG. Serial dilution of placental culture media gave dose-response curves parallel to those of the hCG standard. Gonadotrophin-like activity was detected in cultures of placentae from different stages of gestation, and a biphasic variation appeared: the first peak of activity was present at Day $12(0.853$ \pm 0.070 mi.u. hCG) while the second appeared on Day 17 of gestation $(0.595 \pm$ 0.093 mi.u. hCG). These results suggest that the mouse placenta is capable of secreting a gonadotrophin-like factor in vitro.
\end{abstract}

\section{Introduction}

In the mouse the presence of a functional ovary is required for the maintenance of pregnancy throughout the entire period of gestation. The trophic support of the ovary in early pregnancy is derived from the pituitary, but appears to be under the control of extrahypophysial factors in the second half of pregnancy because maternal hypophysectomy after Day 10 of gestation does not cause termination of pregnancy (Choudary \& Greenwald, 1969). However, these extrahypophysial factors have not been clearly identified in the mouse.

It has been suggested that the trophic support of the ovary, in the second half of pregnancy, may be of placental origin since mouse placenta exhibits both mammotrophic and gonadotrophic activities (Kohmoto \& Bern, 1970; Okker-Reitsma, 1978), although the presence of chorionic gonadotrophin in the mouse placenta has not been firmly established.

Murr, Bradford \& Geschwind (1974), using an antiserum raised against rat LH, could not detect any cross-reactivity in extracts of mouse placentae from Days 9 to 19 of gestation, but Wide \& Hobson (1978), Wide \& Wide (1979) and Okker-Reitsma \& Wilson (1980) have reported the presence of chorionic gonadotrophin in the mouse placenta during pregnancy, although the temporal patterns of occurrence of the hormone differed. This disparity could result from the different experimental techniques employed. Wide \& Wide (1979) assayed the chorionic gonadotrophin in the extracts of mouse placenta by a radioimmunoassay for hCG; because an immunoreactive parallelism between placental extracts and the hCG standard could not be established, the values for mouse placental chorionic gonadotrophin could only be given in arbitrary units. Okker-Reitsma \& Wilson (1980) on the other hand used a bioassay in which placental explants stimulated the synthesis of testosterone in the fetal testis. This testosterone 
production was used as an indicator of chorionic gonadotrophin secretion by the placenta. The testosterone values, however, were not calibrated against a chorionic gonadotrophin standard.

The present study was undertaken to reinvestigate the presence of gonadotrophin in the mouse placenta by using a technique different from those employed in the above mentioned studies.

\section{Animals and cultures}

\section{Materials and Methods}

Albino Swiss mice were maintained under controlled conditions of light (06:00-20:00 h), temperature $\left(21^{\circ} \mathrm{C}\right)$ and humidity. Male and female mice were paired for one night. Fertilization was verified by the presence of vaginal plugs on the following morning. This day was designated as Day 1 of gestation.

On various days of pregnancy (Days 10-18), pregnant mice were killed by cervical dislocation. Uterine horns were aseptically excised by Caesarian section. The cord and membranes were dissected under sterile conditions. Each placenta was cut into 4 pieces, washed twice in ice-cold Medium 199 (Difco Laboratories, Detroit, U.S.A.) and cultured in $0.8 \mathrm{ml}$ Medium 199 containing $10 \%$ fetal calf serum (Difco) on a filter (THWP 01400, pore size 0.45 $\mu \mathrm{m}$ : Millipore Corporation, Bedford, U.S.A.) with a metallic prop. Maternal kidney tissues of approximately the same weight as the placental pieces were similarly cultured to serve as control. The cultures were incubated at $37^{\circ} \mathrm{C}$ in an atmosphere of $5 \% \mathrm{O}_{2}-95 \%$ air. The culture media were collected after $24 \mathrm{~h}$ and centrifuged at $5000 \mathrm{~g}$ for $30 \mathrm{~min}$ at $4{ }^{\circ} \mathrm{C}$. The supernatants were immediately frozen at $-30^{\circ} \mathrm{C}$ for later use.

Media from 3 age-matched placental cultures were pooled together and filtered through a Millipore filter (P.T. GC $11 \mathrm{~K} 25$, nominal molecular weight limit 10000 ) at $4^{\circ} \mathrm{C}$ to eliminate all the compounds with a molecular weight of $<10000$ and to concentrate the medium to about $1 / 10$ th the original volume. A preliminary experiment to determine the efficiency of molecular filtration showed that $90 \%$ of the total progesterone present in the culture medium was eliminated during this step.

\section{Mouse Leydig cell testosterone bioassay}

Gonadotrophin activity in the placental culture media was assessed by the production of testosterone by mouse Leydig cells. The cell suspension was prepared by a collagenase digestion technique as described by several authors (Moyle \& Ramachandran, 1973; Dufau, Pock, Neubauer \& Catt, 1976). Two male mice (40-50 days old) were killed by cervical dislocation. The testes were decapsulated and placed in a 50-ml polyethylene tube containing $10 \mathrm{ml}$ Medium 199 with $0.03 \%$ collagenase (Lot 3674, I.C.N. Pharmaceuticals, Inc., Cleveland, U.S.A.) and $0.1 \%$ bovine serum albumin (Lot 2959, I.C.N. Pharmaceuticals, Inc.). The tube was gassed with a mixture of $95 \% \mathrm{O}_{2}-5 \% \mathrm{CO}_{2}$, tightly capped and shaken for $30 \mathrm{~min}$ at $37^{\circ} \mathrm{C}$ in an horizontal position parallel to the direction of shaking. At the end of the incubation $20 \mathrm{ml} 0.9 \%(\mathrm{w} / \mathrm{v}) \mathrm{NaCl}$ were added to the tube and it was gently inverted several times to facilitate the dissociation of the interstitial cells. The tubules were allowed to settle for $10 \mathrm{~min}$ on ice and the supernatant containing the Leydig cells was poured off and filtered through a nylon gauze (pore size 100 $\mu \mathrm{m})$.

The cell suspension was then centrifuged for $10 \mathrm{~min}$ at $100 \mathrm{~g}$ at $4^{\circ} \mathrm{C}$. The pellet of cells was resuspended in $10 \mathrm{ml}$ incubation medium consisting of Medium 199 containing $0.1 \%$ BSA, $0.02 \%$ theophylline (Touzart et Matignon, Vitry S/Seine, France), $0.01 \%$ Lima bean trypsin inhibitor (Lot 7870, I.C.N.), 0.1\% glucose (Prolabo, Paris, France), 100 i.u. heparin $/ \mathrm{ml}$ (Laboratoire Choay, Paris, France) and $0.5 \%$ fetal calf serum (Difco). This medium was designated as the incubation medium. For the standard curves $250 \mu \mathrm{l}$ Leydig cell suspension 
containing $1 \times 10^{6}$ cells were incubated with appropriate amounts of hCG standard (Sigma, Chemical Company, St Louis, U.S.A.) Lot 48C-0093; 2nd I.S. for chorionic gonadotrophin for bioassay). For the unknown samples, $250 \mu \mathrm{l}$ cell suspension were incubated with different volumes of the filtered culture media.

The total volume was made up to $500 \mu \mathrm{l}$ in all the tubes. All incubations were carried out in tightly stoppered plastic tubes which were gassed with $95 \% \mathrm{O}_{2}-5 \% \mathrm{CO}_{2}$ and incubated for $3 \mathrm{~h}$ at $37^{\circ} \mathrm{C}$. At the end of incubation the tubes were centrifuged for $15 \mathrm{~min}$ at $3000 \mathrm{~g}$. The supernatant was stored at $-30^{\circ} \mathrm{C}$ before being assayed for testosterone content.

\section{Testosterone assay}

Testosterone was assayed directly in the thawed supernatants, using a specific antibody to testosterone (Institut Pasteur Production, No. 79550, Lot B1) and $\left[1,2,6,7-{ }^{3} \mathrm{H}\right]$ testosterone (sp. act. $92 \mathrm{Ci} / \mathrm{mmol}$; Radiochemical Centre, Amersham, U.K.). Testosterone values obtained in unextracted medium did not differ from those obtained after ether extraction. To avoid the effect of proteins in the supernatant a volume of incubation medium, the same as that used for the unknown samples, was added to all the tubes of the standard curve. The main cross-reacting steroid at $50 \%$ of binding was $5 \alpha$-dihydrotestosterone (36\%). However, the results are expressed only in terms of testosterone concentrations because the amounts of $5 \alpha$-dihydrotestosterone produced are very small compared to those of testosterone (Purvis, Clausen \& Hansson, 1978).

\section{Statistical analysis}

The non-parametric Spearman test was used to demonstrate a significant relationship for testosterone production in response to the hCG standard or the placental culture media. Comparisons of the dose-effect curves of the hormone standard and the unknown CG samples were made by means of a parallel line assay (Finney, 1971). The linearization of the dose-response curves was obtained after logarithmic transformation. Analysis of variance was performed for tissues from mice at Days 11, 13 and 15 of gestation and the assumptions of linearity and parallelism of the log dose-response curves were analysed at the $5 \%$ significance level by using an $\mathrm{F}$ test. The potencies of placental culture media from Day 10 to Day 18 of gestation were estimated in the same bioassay, in reference to the same standard curve, using equal volumes of pooled and filtered media as described above. The stimulatory effects of placental culture media were compared to those obtained with the hCG standard preparation and expressed in terms of gonadotrophin-like activity. The influence of gestational age on the values thus obtained was tested by analysis of variance. With significant $F$ values the differences between the means were analysed by $t$ test based on the residual variance.

\section{Results}

Typical dose-response curves for two different hCG standard preparations in the mouse Leydig cell assay are shown in Text-fig. 1. Parallel standard curves were obtained with hCG from Sigma and the 2nd International Standard for hCG. The lower limit of detection was 0.05 mi.u. for the two standard preparations. The intra-assay and interassay variations were 7 and $19 \%$ respectively.

Culture medium from the control kidney tissue gave no stimulation above basal testosterone values (Text-fig. 2). In contrast, culture medium from placental tissue stimulated the production of testosterone by the dispersed Leydig cells. The correlation between testosterone response and log of hCG standard or placental culture media was significant on Day 11 (standard hCG, $P<$ 0.01 ; sample, $P<0.01$ ), Day 13 (standard hCG, $P<0.01$; sample, $P<0.01$ ) and Day 15 of 


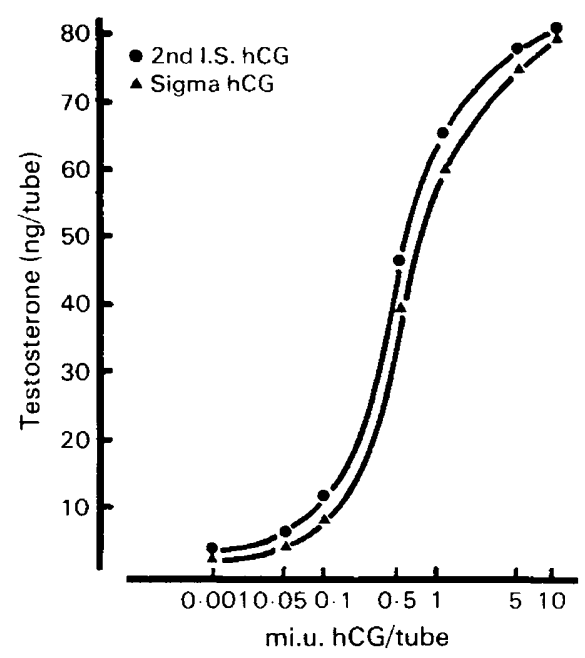

Text-fig. 1. Testosterone production by isolated mouse Leydig cells after $3 \mathrm{~h}$ incubation with increasing concentrations of hCG standard preparations.
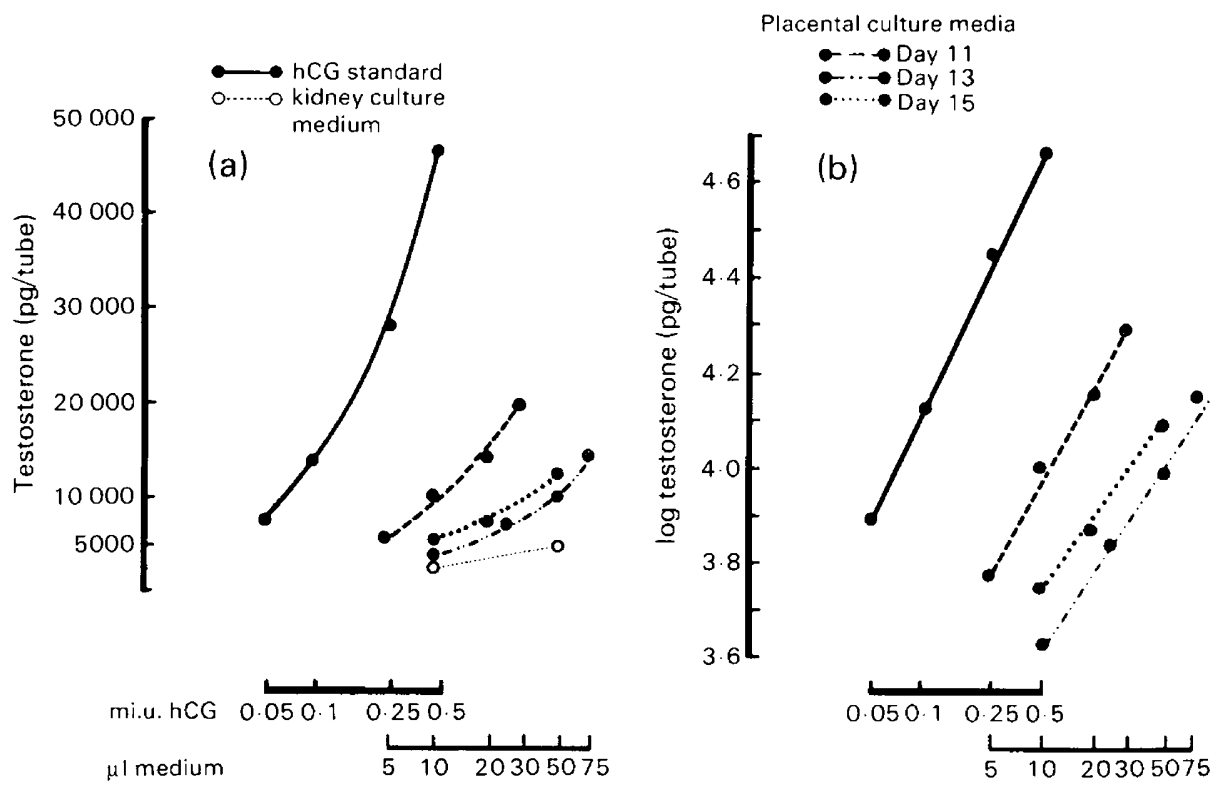

Text-fig. 2. Testosterone production by isolated Leydig cells after incubation with hCG standard, aliquots of placental culture media, and kidney culture media. The stimulatory effect of these preparations was analysed in the same experiment. Each value is the mean of duplicate estimates. Dose-response curves are given (a) before and (b) after linearization by logarithmic transformation.

pregnancy (standard hCG, $P<0.01$; sample, $P<0.05$ ). Serial dilutions of culture media from placentae on Days 11, 13 and 15 of pregnancy, after molecular filtration and concentration, gave dose-response lines parallel to that of standard hCG (Text-fig. 2) as established by analysis of variance according to Finney's criteria (Table 1). 
Table 1. Analysis of variance on dose-response curves for mouse placental culture media and the hCG standard

\begin{tabular}{lrll}
\hline & \multicolumn{1}{c}{ Regression } & \multicolumn{1}{c}{ Linearity } & Parallelism \\
\hline Day 11 & $206.7(1-11)^{*}$ & $0.44(4-11)$ & $0.48(1-11)$ \\
Day 13 & $91.9(1-11)^{*}$ & $0.046(4-11)$ & $0.15(1-11)$ \\
Day 15 & $664 \cdot 1(1-13)^{*}$ & $0.20(3-13)$ & $2.33(1-13)$ \\
\hline
\end{tabular}

Values are $\mathbf{F}$ values for the degrees of freedom indicated in parentheses.

* Significantly different from zero, $P<0.001$.

The interfering effect of steroids in the bioassay for gonadotrophins is shown in Text-fig. 3 . When steroids such as progesterone, dehydroepiandrosterone and androstenedione were added in physiological concentrations to the incubation tubes, they were converted to testosterone by the dispersed Leydig cells. There was a good correlation between the amount of progesterone added and the production of testosterone $(y=0.505 x+265 ; r=0.986 ; P<0.01 ; n=6)$. However, the mean slope values with $95 \%$ confidence limits, were $0.689(0.647-0.731, n=9)$ for the hCG standard and $0.308(0.275-0.340, n=4)$ for the steroids and are significantly different $(P<0.01)$.

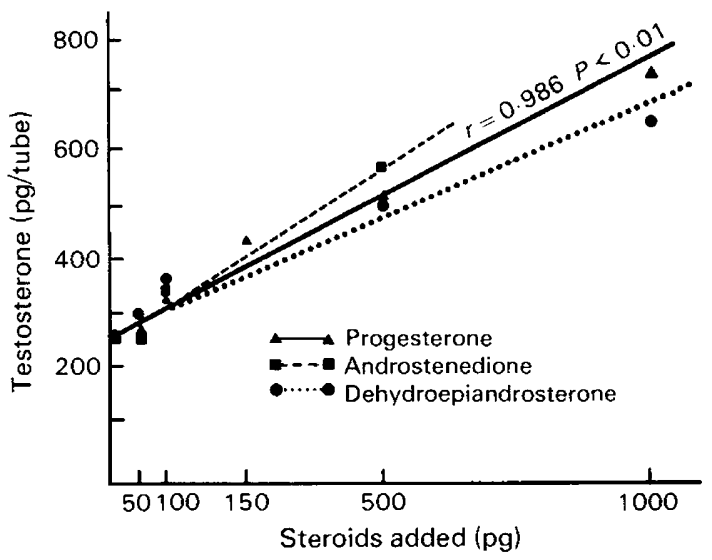

Text-fig. 3. Correlation between different amounts of progesterone, androstenedione, and dehydroepiandrosterone added to the incubation vials, and testosterone production by dispersed mouse Leydig cells.

The pattern of gonadotrophin-like activity in the culture media of placentae from Days 10 to 18 of pregnancy is illustrated in Text-fig. 4 . The activity estimated by bioassay was detected in all placental culture media. Analysis of variance showed a significant effect of age $\left(\mathrm{F}_{(8,16)}=3.5\right.$, $P<0.025)$. Values were highest on Days 11 and 12 of pregnancy $\left(t_{(16)}=3.58, P<0.01\right)$. No significant differences were observed from Day 13 to Day 16. A second rise in gonadotrophin-like activity was observed on Days 17 and 18, although these values remained lower than the peak values observed on Days 11 and 12 of gestation. 


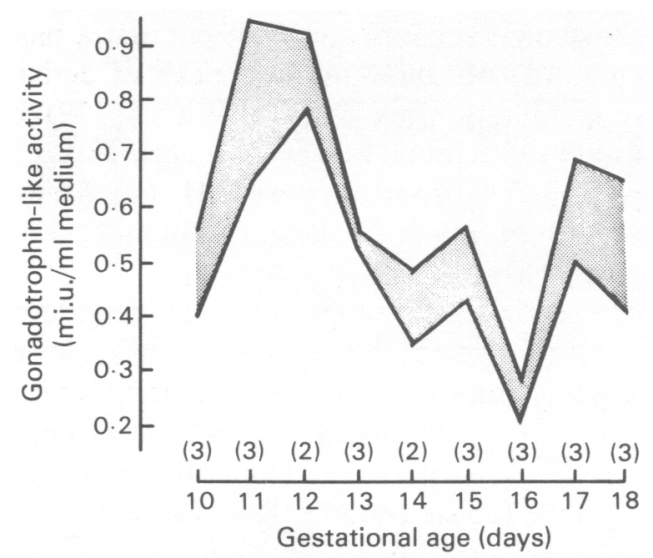

Text-fig. 4. Gonadotrophin-like activity in culture medium of placenta during the second half of gestation. Shaded area indicates the extent of the s.e.m. values. The number of pools measured for each gestational age is indicated in parentheses. Each pool comprised media from 3 individual cultures of placenta from the same pregnant mouse.

\section{Discussion}

Using a sensitive in-vitro bioassay we have been able to show the presence of gonadotrophin-like activity in placental culture media throughout the second half of pregnancy in the mouse. The biological similarity of this gonadotrophin factor in the culture media to human chorionic gonadotrophin is suggested by the fact that aliquots of the media stimulate testosterone synthesis in dispersed Leydig cells of the mouse. Moreover, serial dilution of the culture media yielded dose-response curves parallel to those of the hCG standard.

Molecular filtration was used to eliminate steroids which might otherwise have interfered in the bioassay. This method removes about $90 \%$ of the total steroids present in the culture media. The contribution of the $10 \%$ residual steroids towards the amount of testosterone measured in the bioassay is very low as compared to the increase of testosterone induced by the culture media. The importance of this step cannot be overemphasized especially when biological fluids or tissue extracts from pregnant animals are being assayed. Indeed a large number of steroids, even in the absence of $\mathrm{LH}$ or hCG, can be quantitatively converted into testosterone by mouse Leydig cells. The pattern of rat chorionic gonadotrophin concentrations during pregnancy followed the same curve as did the serum progesterone values (Gnodde, van Dieten, van Rees \& Rothchild, 1979).

Since the mouse Leydig cell testosterone assay does not distinguish between pituitary LH and chorionic gonadotrophin the possibility that the activity measured in the culture media is of pituitary origin must be considered, but seems unlikely. Firstly, this activity in maternal kidney cultures used as control is below the limit of detection. Secondly, the pattern of LH levels in the peripheral blood during gestation in the mouse (Murr et al., 1974) does not correspond to that of gonadotrophin-like activity in placental cultures. Lastly, we could not detect LH activity in placental culture media from different stages of pregnancy, when determined by a double antibody radioimmunoassay procedure employing NIAMDD rat LH-RP1 as standard (unpublished data). In addition, no LH activity was detected either in the mouse placentae from Day 9 of pregnancy to parturition (Murr et al., 1974) or in the rat placenta (Chowdhury \& Steinberger, 1976). We therefore conclude that the gonadotrophin-like activity measured in the placental culture media is not of pituitary origin but is most probably derived from the placenta itself. 
Our results agree with those of Wide \& Wide (1979) in that a biphasic pattern of chorionic gonadotrophin activity occurs. We observed the first peak of activity in culture media from placentae of 11- and 12-day gestations, while Wide \& Wide (1979) found the peak value at 11 days. Okker-Reitsma \& Wilson (1980) found low activity at this stage of gestation. The presence of gonadotrophin-like factor, different from pituitary LH, has been also demonstrated in the placenta, amniotic fluid and serum of rats in the second half of gestation (Haour, Tell \& Sanchez, 1976; Blank, Dufau \& Friesen, 1979).

Attribution of any definite physiological role to the peak gonadotrophic activity at 11 or 12 days of gestation would, at this stage, be purely speculative. However, (1) peak activity in placental gonadotrophic activity occurs at a time in pregnancy when the pituitary is no longer required, suggesting that the trophic support of the ovary has changed to the placenta; (2) progesterone concentration in the ovarian venous blood also exhibits a biphasic pattern during the second half of pregnancy in the mouse (Pointis, Rao, Latreille, Mignot \& Cedard, 1981), the first peak of progesterone concentration being on Day 12 of gestation suggesting placental stimulation of ovarian steroidogenesis; and (3) the development of male phenotype is dependent on androgens secreted by the fetal testes (Jost, 1947). In turn androgen secretion of the fetal testis seems to be under gonadotrophic control. Weniger \& Zeis (1975) have shown that mouse fetal testes are sensitive to exogenous gonadotrophin stimulation as early as Day 12 of gestation. Indirect evidence suggests that the mouse placenta is impermeable to maternal LH (Rajaniemi \& Niemi, 1974). Moreover, LH activity was undetectable in blood of 14-day-old mouse fetuses (Pointis, Latreille \& Cedard, 1980). In view of these observations we are tempted to suggest that the peak of placental gonadotrophic activity observed on Days 11 and 12 of pregnancy provides a primary stimulus for initiating testosterone production in the fetal testes. This stimulation is later augmented by fetal pituitary LH. The importance of placental hCG in stimulating the production of fetal testicular testosterone has been previously reported for man (Clements, Reyes, Winter \& Faiman, 1976).

Our data therefore suggest that the mouse placenta secretes a gonadotrophin-like factor. Although this factor displays a biological similarity to hCG, the final test of its identity to hCG requires its isolation and the determination of its chemical structure.

We thank M.-T. Latreille and T.-M. Mignot for technical assistance; W.H.O., the National Institute for Biological Standards and Controls, London, for the hCG standard; Dr M. $\mathrm{O}$. Richard and Dr P. d'Athis (Laboratoire de Pharmacologie Biochimie, Hôpital SaintVincent-de-Paul, Paris, France) for statistical analyses and M. Verger for help with the manuscript. B.R. is grateful to I.N.S.E.R.M. for a fellowship. This work was supported by a grant from I.N.S.E.R.M., France (ATP No. 56.78.88).

\section{References}

Blank, M.S., Dufau, M.L. \& Friesen, H.G. (1979) Demonstration of potent, gonadotrophin-like biological activity in the serum of rats during midpregnancy. Life Sci. 25, 1023-1028.

Choudary, J.B. \& Greenwald, G.S. (1969) Ovarian activity in the intact or hypophysectomized pregnant mouse. Anat. Rec. 163, 359-372.

Chowdhury, M. \& Steinberger, E. (1976) Pituitary and plasma levels of gonadotrophins in foetal and newborn male and female rats. J. Endocr. 69, 381-384.

Clements, J.A., Reyes, F.I., Winter, J.S.D. \& Faiman, C. (1976) Studies on human sexual development. III.
Fetal pituitary and serum, and amniotic fluid concentrations of LH, CG, and FSH. J. clin. Endocr. Metab. 42, 9-19.

Dufau, M., Pock, R., Neubauer, A. \& Catt, K.J. (1976) In vitro bioassay of LH in human serum: the rat interstitial cell testosterone (RICT) assay. J. clin. Endocr. Metab. 42, 958-969.

Finney, D.J. (1971) Statistical Methods in Biological Assay, 2nd edn. Griffin and Co., London.

Gnodde, H.P., van Dieten, A.M.J., van Rees, G.P. \& Rothchild, I. (1979) Conversion of progesterone to testosterone in the rat Leydig cell. Proc. Soc. exp. Biol. Med. 160, 130-133. 
Haour, F., Tell, G. \& Sanchez, P. (1976) Mise en évidence et dosage d'une gonadotrophine chorionique chez le rat (rCG). C. r. hebd. Séanc. Acad. Sci., Paris D 282, 1183-1186.

Jost, A. (1947) Recherches sur la differenciation sexuelle de l'embryon de lapin. Archs Anat. microsc. Morph. exp. 36, 242-270.

Kohmoto, K. \& Bern, H.A. (1970) Demonstration of mammotrophic activity of the mouse placenta in organ culture and by transplantation. J. Endocr. 48, 99-107.

Moyle, W.R. \& Ramachandran, J. (1973) Effect of LH on steroidogenesis and cyclic AMP accumulation in rat Leydig cell preparations and mouse tumor Leydig cells. Endocrinology 93, 127-134.

Murr, S.M., Bradford, G.E. \& Geschwind, I.I. (1974) Plasma luteinizing hormone, follicle-stimulating hormone and prolactin during pregnancy in the mouse. Endocrinology 94, 112-116.

Okker-Reitsma, G.H. (1978) Secretion of gonadotrophin by the mouse placenta in vitro. In Comparative Endocrinology, pp. 85-86. Eds P. J. Gaillard \& H. H. Boer. Elsevier, Amsterdam.

Okker-Reitsma, G.H. \& Wilson, G.L. (1980) Evidence for a biphasic pattern in gonadotrophin secretion by the mouse placenta in vitro. J. Steroid Biochem. 12, 97-99.
Pointis, G., Latreille, M.-T. \& Cedard, L. (1980) Gonado-pituitary relationships in the fetal mouse at various times during sexual differentiation. J. Endocr. $86,483-488$.

Pointis, G., Rao, B., Latreille, M.-T., Mignot, Th.-M. \& Cedard, L. (1981) Progesterone levels in the circulating blood of the ovarian and uterine veins during gestation in the mouse. Biol. Reprod. 24, 801-805.

Purvis, K., Clausen, O.P.F. \& Hansson, V. (1978) Age-related changes in responsiveness of rat Leydig cells to hCG. J. Reprod. Fert. \$2, 379-386.

Rajaniemi, H.J. \& Niemi, M. (1974) Distribution of pituitary gonadotropins ( $\mathrm{LH}$ and $\mathrm{FSH}$ ) in pregnant mice and their penetration into the fetuses: wholebody autoradiographic study. Steroids Lipids Res. 5, 297-307.

Weniger, J.P. \& Zeis, A. (1975) Effet des gonadotrophines sur la synthèse d'androgènes par les testicules embryonnaires de souris et de rat. Archs Anat. microsc. Morph. exp. 64, 61-66.

Wide, L. \& Hobson, B. (1978) Chromatographic studies on a chorionic gonadotropic activity in the placenta of the rat, mouse and hamster. Upsala J. Med. Sci. 83, $1-6$.

Wide, L. \& Wide, M. (1979) Chorionic gonadotrophin in the mouse from implantation to term. J. Reprod. Fert. 57, 5-9. 